\title{
Notch-sensitivity of hybrid carbon-fibre/self-reinforced polypropylene composites
}

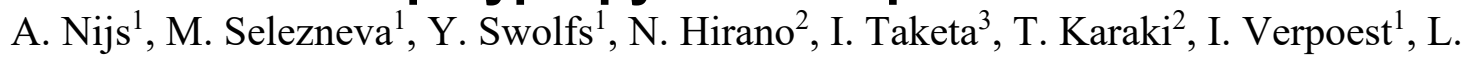 \\ Gorbatikh $^{1}$ \\ ${ }^{1}$ Department of Materials Engineering, KU Leuven, Kasteelpark Arenberg 44 box 2450, \\ 3001 Leuven, Belgium \\ ${ }^{2}$ Composite Materials Research Laboratories, Toray Industries, Inc., 1515 Tsutsui \\ Masaki-cho Iyogun, 791-3193 Ehime, Japan \\ ${ }^{3}$ Technical Center, Toray Carbon Fibers Europe S.A. (CFE), Route Départementale 817, \\ 64170 LACQ, France
}

Keywords: A. Hybrid composites; B. Fragmentation; C. Notch; C. Damage tolerance; Pseudo-ductility

\section{Abstract}

Hybrid composites combining brittle and ductile reinforcing fibres can be designed to have pseudo-ductile behaviour by controlling their failure mechanisms. The recently developed carbon-fibre/self-reinforced polypropylene (SRPP) hybrids have demonstrated a unique combination of stiffness ( $7 \mathrm{GPa})$, toughness ( $>6 \%$ strain) and density $\left( \pm 1000 \mathrm{~kg} / \mathrm{m}^{3}\right)$. Here, the influence of a circular notch on their failure mechanisms is investigated. Discontinuous carbon-fibre/polypropylene composites retained $69 \%$ of the gross strength and $83 \%$ of the net strength. The strength retention of SRPP was highly influenced by the processing parameters, and a notch-insensitive composite could be produced. Pseudo-ductility was obtained even with the notched hybrids. Hybrids that do not achieve the optimal ductility, still exhibit high gross and net strength retentions and can be classified as notch-insensitive. These results illustrate the significant potential of this new hybrid composite for applications with notches or holes.

\section{Introduction}

Notches have a substantial influence on the behaviour of a material in a stressed state.

When a notch is present in a loaded material, it will act as a stress concentrator, changing the stress distributions and possibly altering the active damage mechanisms. This can significantly reduce the strength of the material. The notch sensitivity of a material is a measure that represents how much the presence of a notch or other geometric discontinuity affects the material. The ability to deform plastically near the 
notch is a vital factor that governs notch sensitivity [1], but which is often absent in composites. Instead, composites can partially blunt the stress concentrations by creating damage near the notch, such as transverse cracks, fibre-matrix debonding, fibre pull-out and delaminations. The exact damage mechanisms depend strongly on the layup configuration and material combination $[2,3]$. Nevertheless, composites tend to be more notch sensitive than most metals. Besides being an important design parameter, notch sensitivity can be used as a measure for damage tolerance as well as toughness [4].

An example of the theoretical stress distribution around a hole for an ideally brittle and perfectly plastic materials are depicted in Figure 1a and b. In the case of the brittle material, a high stress concentration occurs near the hole and gradually reduces towards the edges. In the case of a ductile material with perfect plasticity, the stresses are redistributed across the width. A perfectly plastic material would be notch-insensitive, meaning the failure stress is proportional to the net section. Figure 1c displays the resultant strength retention as a function of the hole diameter D over specimen width $\mathrm{W}$ ratio $(\mathrm{D} / \mathrm{W})$ for both types of materials. The notched behaviour of composites is typically between these bounds and is influenced by the hole-size, composite layup and thickness [3-8].

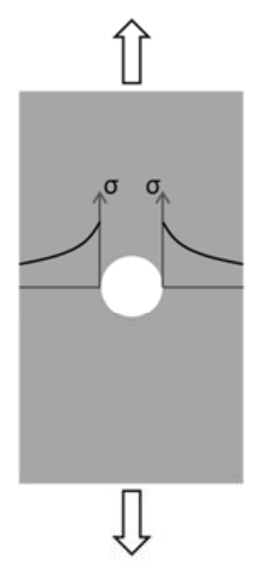

(a)

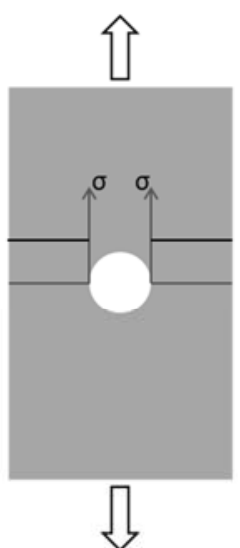

(b)

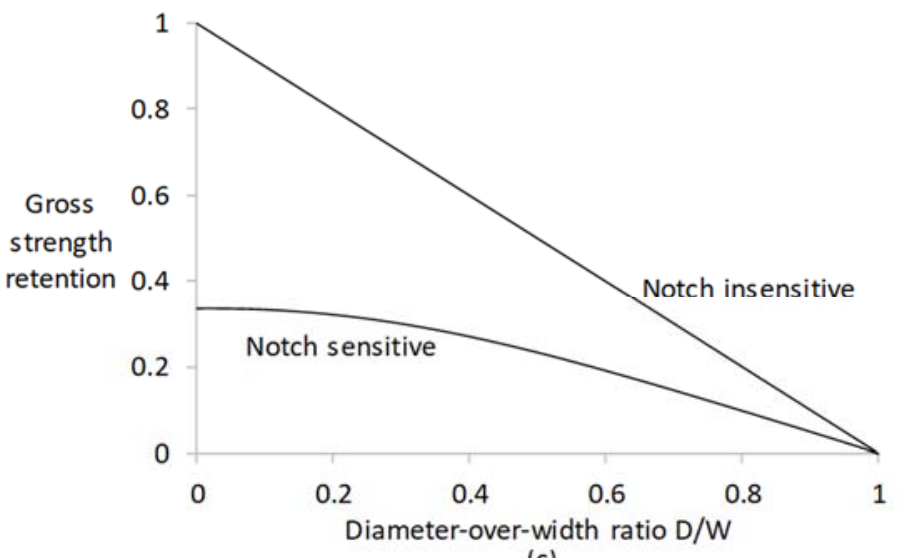

(c)

Figure 1: Notch sensitivity of materials: a) stress distribution in a plate with a notch for a notchsensitive or purely brittle material, b) stress distribution in a plate with a notch for a notchinsensitive or ductile material with perfect plasticity, and c) relationship between gross strength retention and diameter-over-width ratio based on Pilkey's equations [9].

Conventional carbon or glass fibre composite materials offer excellent stiffness but typically exhibit brittle failure modes. On the other hand, self-reinforced composites 
have a matrix and a reinforcement that are made from the same polymer and are known for their high toughness and failure strain [10-13]. However, their stiffness and yield strength are too low for applications that bear significant loads. This stiffness-toughness dilemma has sparked the development of pseudo-ductile hybrid composite materials that combine the benefits of two fibre types. For instance, self-reinforced polypropylene (SRPP) hybridised with discontinuous carbon fibres can achieve a twofold increase in modulus and fourfold increase in the yield stress over SRPP while maintaining failure strain over $6 \%$ [14]. It therefore enables higher specific stiffness and yield stress, which can lead to weight reductions. The addition of carbon fibre to SRPP does limit the excellent recyclability of SRPP to downcycling into for example injection-moulding compounds. Those downcycled compounds do have a higher value than downcycled SRPP compounds thanks to the carbon fibres increasing the mechanical properties. The notch-sensitivity of such composites is yet to be studied.

The unique combination of pseudo-ductile tensile properties was achieved by carefully controlling the failure mechanisms and taking advantage of the difference in failure strains between the two reinforcements [14-16]. The behaviour of these hybrids is schematically depicted in Figure 2 and is termed as pseudo-ductile. The damage scenarios that can occur in hybrids were outlined by Czél et al. $[17,18]$ and Swolfs et al. [15] (see Figure 2). The possible damage events that can occur after the initial failure of the brittle carbon layer $[15,17,18]$ :

a) instant failure of the SRPP layer as it cannot sustain the load that is transferred to it (see Figure 2a),

b) delamination (first unstable and then stable), which is followed by the failure of the SRPP (see Figure 2b),

c) stable fragmentation of the carbon layer until saturation and then failure of the ductile SRPP material (see Figure 2c). 


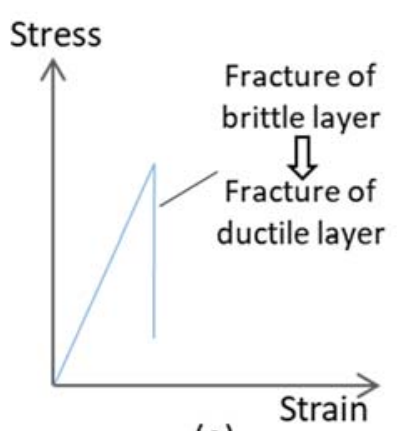

(a)

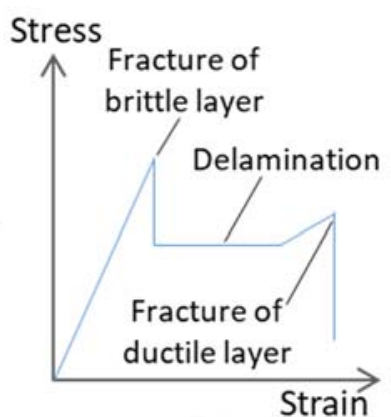

(b)

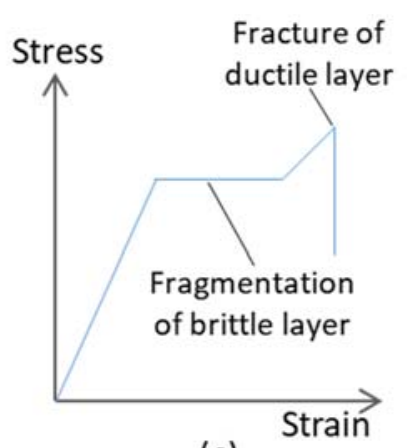

(c)

Figure 2: Stress-strain diagrams corresponding to the different failure events after the fracture of the brittle carbon layer: a) failure of the ductile SRPP layer b) complete delamination and c) stable fragmentation of the ductile layer (figure based on [18]).

$\mathrm{Wu}$ and Lai [19] studied open-hole tension (OHT) properties of woven self-reinforced polyethylene terephthalate (PET) composites. Interestingly, net strength retention was unaffected by the hole size and was around $80 \%$ for all the test cases. No delaminations were observed, which is attributed to the good interfacial bonding. Apart from the absence of delaminations, the failure occurred relatively similar to conventional woven composites: by fibre breakage, failure and pull-out of longitudinal yarns, and splitting fracture of transverse yarns [19]. The high strength retention in the presence of a notch is a promising result, but more research on the notch sensitivity of self-reinforced composites is necessary for a better understanding.

Discontinuous fibre composites tend to have lower mechanical performance, but easier processing and lower cost than continuous fibre composites. Discontinuous fibre composites are generally considered to be notch sensitive due to their small damage zone characteristics and poor crack bridging capabilities, leading to limited notch blunting [4]. Some studies have reported that longer fibres can allow for more stress redistributions around the notch and lead to higher notched strength retention $[4,20]$. Another study on carbon/epoxy composites with randomly oriented fibres showed no difference in the notch sensitivity between the samples with 1, 5 and $15 \mathrm{~mm}$ long fibres [21]. Other authors [22,23] reported low notch sensitivity of glass-fibre sheet moulding compounds (SMC) with $25 \mathrm{~mm}$ long fibres in a vinylester or polyester matrix. These types of materials contain many intrinsic flaws (such as voids or fibre ends), which by 
themselves already reduce the strength of SMCs. Hence, failure of notched SMCs is more sensitive to the presence of these intrinsic flaws rather than to the notch. Several studies on discontinuous carbon fibre composites produced from randomly oriented strands or bundles [24], also reported low notch sensitivity. These composites are inherently highly heterogeneous, leading to high internal stress concentrations. These materials are sometimes deemed to be notch-insensitive, as they may fail in the grosssection away from the hole due to their large strength variability [5]. Overall, there is a large spread in the reported notch sensitivity of discontinuous fibre composites. Net strength retention ranges from $50 \%$ to $100 \%[4,5,20,24]$, and measurements show a high degree of scatter, which makes it difficult to establish trends in the behaviour. Hence, it is not yet possible to make clear conclusions about the notched behaviour of randomly oriented fibre composites.

Hybrids comprising of continuous aramid/glass [25], and glass/carbon [26] fibre weaves can be optimised to achieve higher net strength retention than the nominal non-hybrid composites. Czél et al. [27] investigated notch sensitivity of carbon/carbon pseudoductile hybrids. Two types of hybrids were considered that contained the same low elongation carbon fibres (XN-80 with $0.5 \%$ failure strain) but different high-elongation carbon fibres (T1000 with 2.2\% or MR60 with 1.9\% strain). Both hybrids showed notch-insensitive behaviour. However, the T1000/XN-80 hybrid showed gradual OHT failure, while the MR60/XN-80 hybrid failed in a more brittle manner. This difference was at least partially attributed to the higher mode II fracture toughness of the MR60/XN-80 hybrid, which suppressed interfacial damage and limited stress redistributions. The difference in failure strain also plays a role, as it has been acknowledged that a larger difference in strains between the two fibres in the hybrid leads to a larger hybrid effect $[28,29]$. Overall, hybridisation is regarded as a means of reducing the notch sensitivity of composites. Pseudo-ductile hybrids, in particular, are expected to exhibit low notch sensitivity, since their inherent ductile behaviour is 
attributed to subcritical damage mechanisms, which are expected to effectively

redistribute high stress concentrations.

The current paper investigates the notch sensitivity of three types of composites: discontinuous carbon-fibre/polypropylene (PP) composites, SRPP composites and their hybrids. These hybrids have some of the highest pseudoductile strains reported in the literature to date, with values up to $17 \%$, compared to the typical $1-3 \%$ in the literature [27]. The goal of this work is to evaluate, understand and compare the notched behaviour and failure mechanisms that are characteristic to SRPP, discontinuous carbon composites and carbon/SRPP hybrids. OHT tests were performed and analysed to gain insight into the notch sensitivity of each material, especially for the materials with high pseudo-ductile strains.

\section{Experimental methodology}

\subsection{Materials and processing}

Composite panels were fabricated using discontinuous carbon fibre mats, PP films and woven PP-tape fabrics. Woven PP fabrics were provided by Propex Fabrics GmbH, had a 2/2 twill architecture and an areal density of $130 \mathrm{~g} / \mathrm{m}^{2}$. Discontinuous carbon fibres were provided by Toray Industries, Inc in the form of a dry random mat with $6 \mathrm{~mm}$ long T700S fibres and an areal weight of $30 \mathrm{~g} / \mathrm{m}^{2}$. Propex Fabrics $\mathrm{GmbH}$ also provided 20 $\mu \mathrm{m}$ thick PP films of the same grade. These films were used to impregnate the random mats, and in one layup they were interleaved with woven PP fabrics to create a better bonding between the layers [11].

Table 1 presents an overview of the tested laminates, with their lay-up and carbon fibre volume fraction $\left(\mathrm{V}_{\mathrm{f}}\right)$. The fibre volume fractions were calculated based on the density, areal weight and thickness of the produced composites. Three dispersed hybrids were made with an increasing $V_{\text {f. }}$ A fourth hybrid was made using a 'block' approach where all carbon fibres are in the centre and the SRPP on the outside. It should be noted that one carbon layer includes 4 PP films to provide enough matrix (see Table 1). All 
laminates were manufactured by hot compaction at $188^{\circ} \mathrm{C}$ with a 5 -minute dwell time and at a pressure of 39 bar, resulting in a $320 \times 320 \mathrm{~mm}$ plate. These conditions are based on the optimisation performed by Swolfs et al. [30].

Table 1: Description, lay-up, and carbon volume fraction of the tested materials. ' $S$ ' stands for a layer of woven SRPP fabric, ' $C$ ' represents a layer of a carbon mat with $30 \mathrm{~g} / \mathrm{m}^{2}$ and '/' represents a PP film.

\begin{tabular}{cccc}
\hline Description & Lay-up & $\mathrm{V}_{\mathrm{f}}[\%]$ & Thickness $(\mathrm{mm})$ \\
\hline SRPP & {$[\mathrm{S}]_{16}$} & 0 & $2.38 \pm 0.05$ \\
SRPP with films & $\mathrm{S} /[\mathrm{S} /]_{14} \mathrm{~S}$ & 0 & $2.65 \pm 0.08$ \\
Carbon/PP & {$[/ / \mathrm{C} / /]_{26}$} & 17 & $2.68 \pm 0.02$ \\
Dispersed hybrid 1 & {$[\mathrm{S} / / \mathrm{C} / / \mathrm{S} / / \mathrm{C} / / \mathrm{S} / / \mathrm{C} / / \mathrm{S} / / \mathrm{C} / / \mathrm{S} / / \mathrm{C} / / \mathrm{S}]$} & 6.2 & $1.32+0.03$ \\
Dispersed hybrid 2 & {$\left[\mathrm{S}[/ / \mathrm{C} / /]_{2} \mathrm{~S}[/ / \mathrm{C} / /]_{2} \mathrm{~S}[/ / \mathrm{C} / /]_{2} \mathrm{~S}[/ / \mathrm{C} / /]_{2} \mathrm{~S}[/ / \mathrm{C} / /]_{2} \mathrm{~S}\right]$} & 9 & $1.85 \pm 0.05$ \\
Dispersed hybrid 3 & {$\left[\mathrm{S}[/ / \mathrm{C} / /]_{3} \mathrm{~S}[/ / \mathrm{C} / /]_{3} \mathrm{~S}[/ / \mathrm{C} / /]_{3} \mathrm{~S}[/ / \mathrm{C} / /]_{3} \mathrm{~S}[/ / \mathrm{C} / /]_{3} \mathrm{~S}\right]$} & 10.7 & $2.28 \pm 0.03$ \\
Blocked hybrid & $\mathrm{S} / \mathrm{S} / \mathrm{S}[/ / \mathrm{C} / /]_{10} \mathrm{~S} / \mathrm{S} / \mathrm{S}$ & 8.6 & $1.89 \pm 0.04$ \\
\hline
\end{tabular}

\subsection{Open-hole tension tests}

Tensile tests for unnotched and notched samples were performed according to ASTM

D5766. 4 or 5 tests were performed for every configuration, apart from the SRPP configuration with films, where six specimens were tested for every hole size.

Specimens were $250 \mathrm{~mm}$ long and $36 \mathrm{~mm}$ wide, with a gauge length of $150 \mathrm{~mm}$. Several of the hybrid layups were thinner than 2-4 mm recommended by the ASTM standard, which was the inevitable consequence of balancing consistency in the layup and avoiding production difficulties with thicker specimens. For the notched samples three different diameters were tested: 3, 6, and $12 \mathrm{~mm}$. Specimens were cut using a band saw with small teeth. Holes were cut in the middle of the specimens using brad and spur drill bits on a vertical drilling machine at a speed of $700 \mathrm{rpm}$. The procedure for introduction of a hole was optimized. To minimise delamination during cutting and drilling, a wooden backing plate was used. SRPP is transparent under normal conditions and will become opaque as it gets damaged. By placing it against a backlight, damaged areas observed as darker spots could be assessed. The hole edges showed the typical damage in all samples after drilling: light damage around the whole edge and some pulled-out tape ends (see Figure 3). 


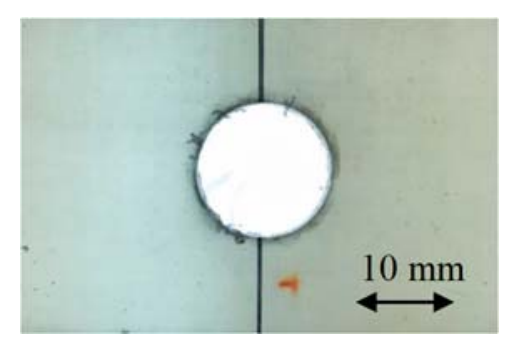

Figure 3: Photo of an SRPP specimen with interleaved films with a $12 \mathrm{~mm}$ hole in a lightbox. The hole was drilled using a modified wood drill bit. The vertical black line was applied with a marker pen and used as a guide for drilling the hole.

All samples were tested on a Zwick Roell z100 testing machine with a $100 \mathrm{kN}$ load cell at a constant displacement rate of $7.5 \mathrm{~mm} / \mathrm{min}$. This corresponds to a nominal strain rate of 5\%/min. Strain was acquired via Digital Image Correlation technique (DIC) by capturing images at a speed of $4 \mathrm{~Hz}$ using a $5 \mathrm{MP}$ camera and then processing them using the GOM Correlate software. One half of the specimens was covered with a black and white speckle pattern to allow for the DIC analysis (see Figure 4). The other half of the specimen was kept unpainted to facilitate tracking the damage development during loading. Global strains were acquired by placing a $120 \mathrm{~mm}$ long digital extensometer away from the hole and hence close to the specimen edge (see purple arrow in Figure 4). As the speckle pattern deteriorated at the higher strain values due to the excessive damage development, a corrected version of the crosshead displacement was used for strain measurement. The method used to correlate crosshead displacement to the specimen strain was previously described in [15]. The gross strength retention $\sigma_{\text {gross }}$ and net strength retention $\sigma_{\text {net }}$ were calculated as:

$$
\sigma_{\text {gross }}=\frac{P}{W . t}
$$

and

$$
\sigma_{n e t}=\frac{P}{(W-D) \cdot t}
$$

where $\mathrm{P}$ is the failure load, $\mathrm{W}$ the specimen width, $\mathrm{D}$ the hole diameter and $\mathrm{t}$ the specimen thickness. 


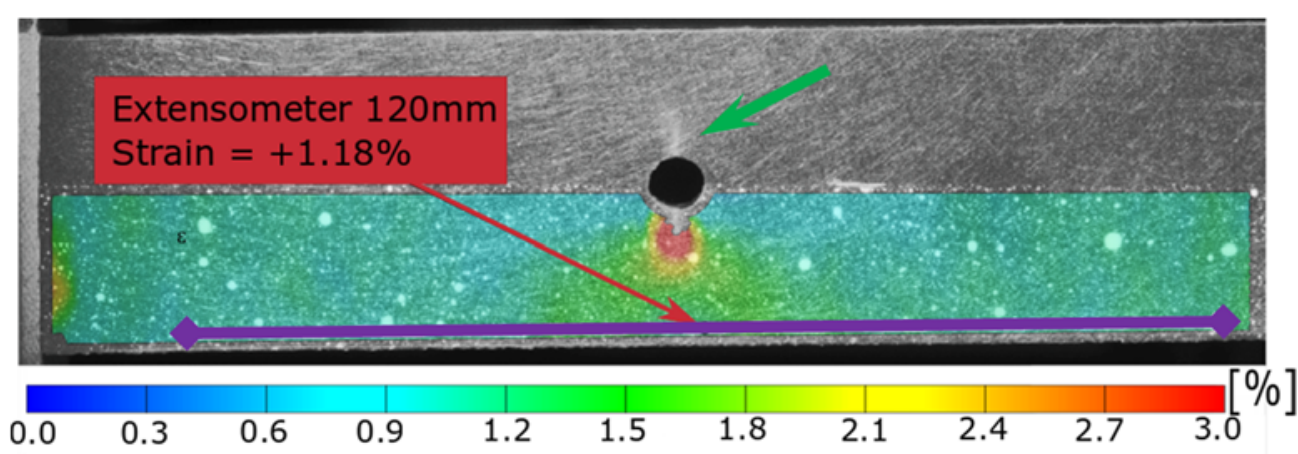

Figure 4: Last image before failure of a notched carbon fibre specimen with the full-field strain distribution as well as the virtual extensometer in purple. The green arrow points to a damaged region.

\section{Results and discussion}

\subsection{Discontinuous fibre composites}

Figure 5 displays the stress-strain diagrams of the carbon/PP specimens with no hole and a $6 \mathrm{~mm}$ hole. These samples fail in a brittle manner. Notched samples demonstrate a gross strength retention of $69 \%$ and a net strength retention of $83 \%$. The development of the crack and the high strain region near the crack tip can be seen in the last image taken before final failure (see green arrow in Figure 4). A maximum local strain of $3.0 \%$ is reached near the notch in Figure 4. Even higher local strain values were found for other specimens or for specimens processed with other DIC parameters. For unnotched specimens, however, local maxima of approximately $2.2 \%$ were observed, which is due to a combination of noise and local material variability. These local maxima can also be seen on the strain field of an individual notched specimen in the regions away from the notch (see Figure 4).

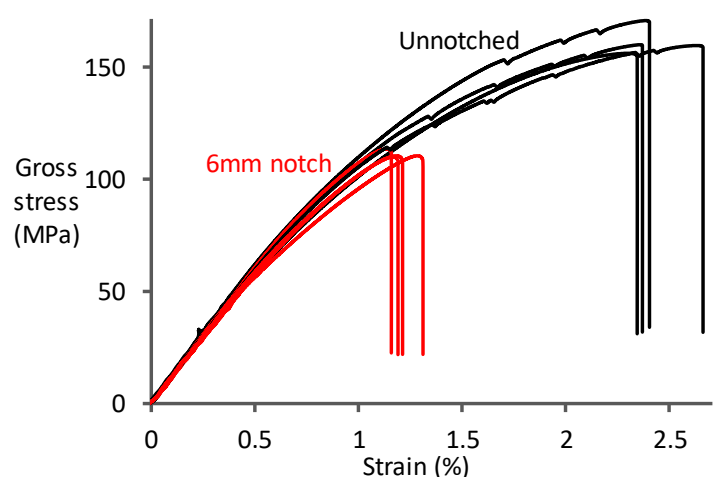

(a)

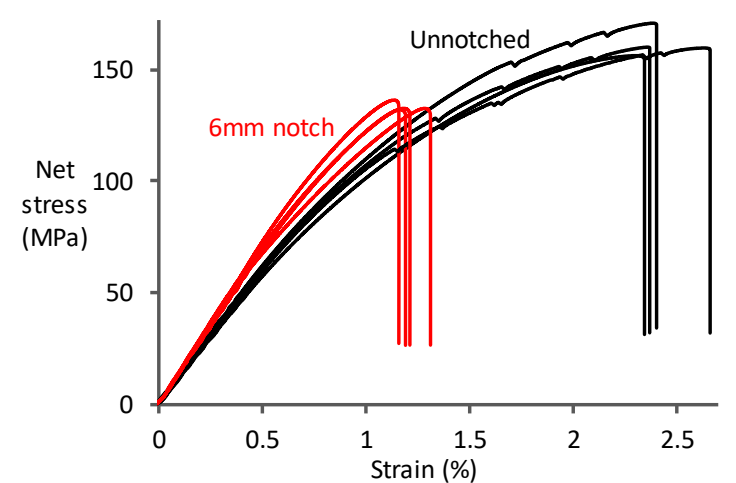

(b)

Figure 5: Stress-strain diagrams of the tensile tests on carbon/PP materials with and without the hole: a) gross and b) net stress. 


\subsection{SRPP}

The effect of extra films on tensile and impact properties of SRPP has been previously reported by Swolfs et al. [11]. In the current work, it was revealed that SRPP samples without films have poor interlaminar bonding and undergo extensive delamination and tape debonding during failure. Such damage development results in a gradual failure of the specimen, which explains the rounded shape of the stress-strain curve (see Figure 6b). Addition of the films improves the interlaminar bonding between the SRPP layers and leads to a better stress transfer between them. Figure 6a reveals that these samples attained a higher ultimate tensile stress (UTS) and failed in a more abrupt manner than samples without films. Minimal delamination was observed.

The notched and unnotched SRPP with films display a sharp load drop at failure (see Figure 6a). The failure region in these samples was localised and tape debonding was limited to the notched zone (see Figure 7a).

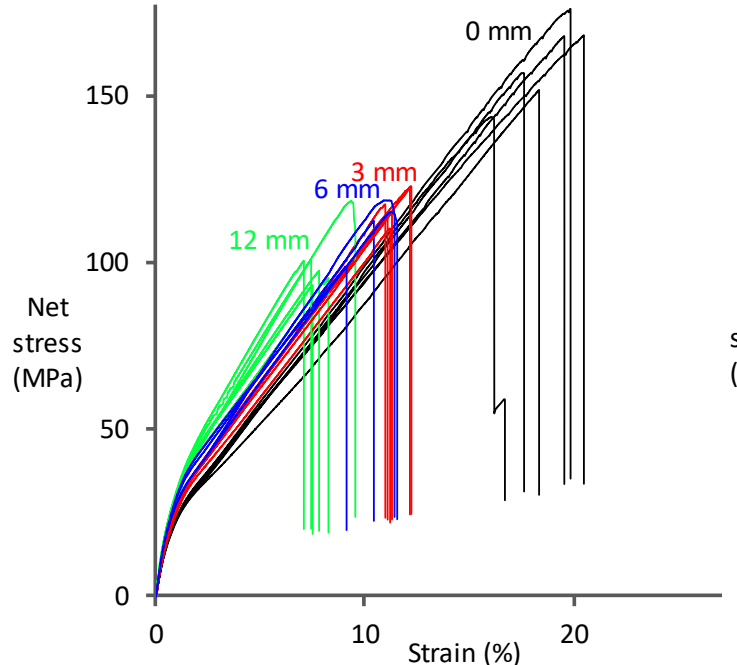

(a)

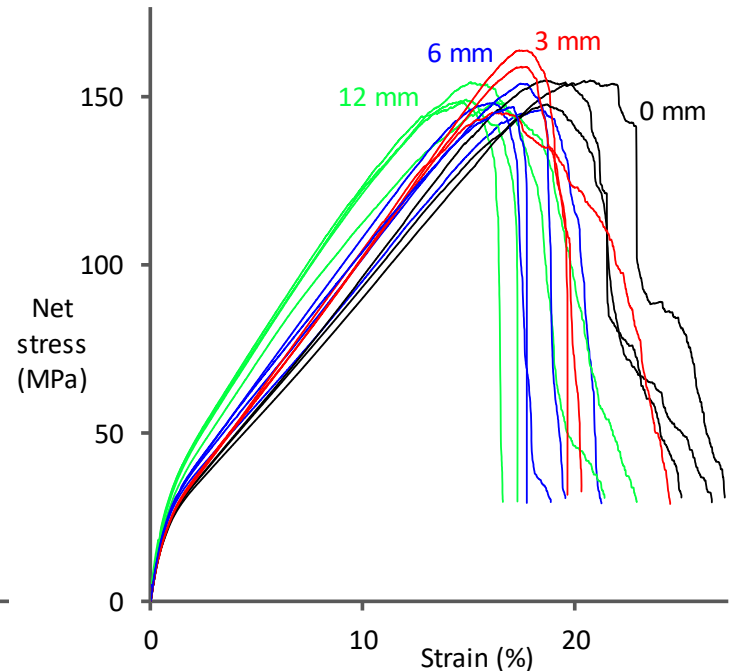

(b)

Figure 6: Net stress-strain diagrams of SRPP specimens a) with films and b) without films.

The stress-strain diagrams of notched and unnotched SRPP without films are displayed in Figure 6b. The net-stress diagrams essentially overlap, implying that the material is notch-insensitive. This notch insensitivity is enabled by the subcritical damage mechanisms that can occur in the material, such as delaminations and tape debonding. As discussed in the introduction, these mechanisms cause a more gradual failure and help to redistribute the stress over a larger area. Figure $7 \mathrm{~b}$ and $\mathrm{c}$ illustrate the extent of 
damage in the samples without films. In these images, the damaged edges of the specimen appear darker than the middle section. In the specimens with films, the darker regions are seen only around the hole (see Figure 7a). It is also evident that samples with films develop a crack originating from the notch, while no clear crack location could be detected in the samples without films.

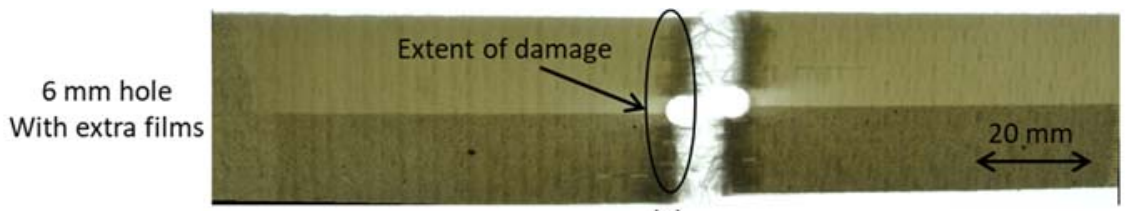

(a)

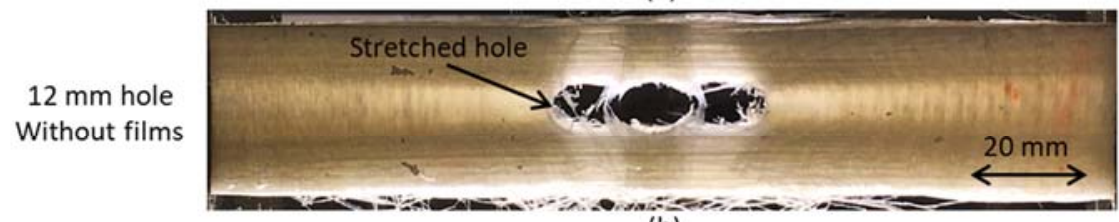

(b)

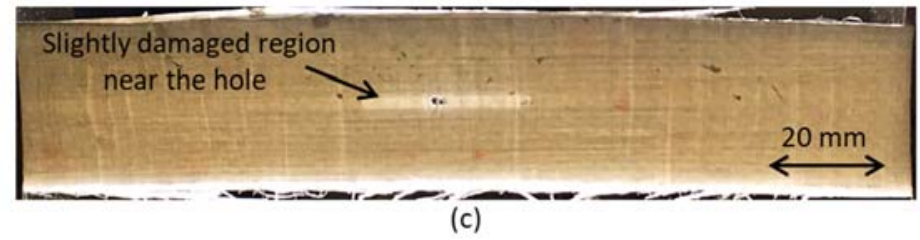

Figure 7: Photos taken after OHT tests of SRPP specimens a) with extra films and with a 6 mm hole, b) without films and with $12 \mathrm{~mm}$ hole and c) without films and with $3 \mathrm{~mm}$ hole.

Moreover, Figure $7 \mathrm{~b}$ reveals that the specimen with a $12 \mathrm{~mm}$ hole has deformed so much, that the hole has split up into three different sections. The left- and right-hand section appear lighter, as they do not contain any transverse tapes anymore. The centre section appears darker, as it still contains transverse tapes that block the light. This confirms that the transverse cracks did not start near the middle of the hole, but at the edge (left- and right-hand side in Figure 7b). In the specimen with $3 \mathrm{~mm}$ hole (see Figure 7c), the hole stretched into a narrow slit and became almost unnoticeable amongst the extensive debonding and fibrillation that develop throughout the specimen. There is only a small slightly undamaged region that extends longitudinally from the hole, and no large transverse cracks are visible (see Figure 7c). Overall, notched samples without films fail in the same manner as the unnotched ones: via delamination, tape debonding and tape breaking. 
All the results are tabulated in Table 2. The strength retention of the notched SRPP samples without films is much higher than that of SRPP with films. In fact, the samples without films can be considered as notch insensitive.

Table 2: Tensile test results of SRPP with and without films.

\begin{tabular}{ccccc}
\hline $\begin{array}{c}\text { Hole diameter } \\
(\mathrm{mm})\end{array}$ & $\begin{array}{c}\text { Gross UTS } \\
(\mathrm{MPa})\end{array}$ & $\begin{array}{c}\text { Strain at UTS } \\
(\%)\end{array}$ & $\begin{array}{c}\text { Gross strength } \\
\text { retention }(\%)\end{array}$ & $\begin{array}{c}\text { Net strength } \\
\text { retention }(\%)\end{array}$ \\
\hline \multicolumn{5}{c}{ SRPP with films } \\
\hline 0 & $161 \pm 12$ & $18.6 \pm 1.7$ & - & - \\
3 & $107 \pm 4$ & $11.5 \pm 0.6$ & 67 & 73 \\
6 & $94 \pm 7$ & $10.5 \pm 1.0$ & 59 & 70 \\
12 & $67 \pm 6$ & $7.9 \pm 0.8$ & 42 & 63 \\
\hline \multicolumn{5}{c}{ SRPP without films } \\
\hline 3 & $153 \pm 4$ & $19.4 \pm 1.2$ & - & - \\
6 & $142 \pm 10$ & $17.0 \pm 0.8$ & 93 & 97 \\
12 & $124 \pm 3$ & $17.3 \pm 1.0$ & 81 & 98 \\
\hline
\end{tabular}

\subsection{Hybrids}

With the behaviour of the discontinuous carbon fibre composite and the SRPP composites known, the hybrids made from these materials can be discussed. Four different hybrids were made with different volume fractions and lay-up (see Table 1). The hybrid composites will first be considered in their unnotched state, where the influence of the carbon fibre volume fraction and different lay-ups is discussed. Next, the behaviour of the hybrids is examined for a $6 \mathrm{~mm}$ diameter hole. The influences of the different parameters will be discussed again, as well as the influence of pseudoductility on notch sensitivity.

\subsubsection{Unnotched}

Figure 8 presents the results of the tensile tests on the unnotched hybrids. The initial region of the curve represents the behaviour of hybrids when the SRPP and carbon fibre layers are well bonded together and elongate uniformly. Hence, the stress-strain response can be estimated using the rule-of-mixtures until the failure of the carbon layer, which occurs at approximately $2 \%$ strain [14]. As the carbon fibre volume fraction increases, the modulus and yield stress increase accordingly. These results are on par with previously published works on these materials [14]. The desired pseudoductile behaviour with failure strains over $9 \%$ was achieved with dispersed hybrids with 
$V_{f}$ of $6.2 \%$ and $9 \%$. A ductile-to-brittle transition was observed for $V_{f}$ in between $9 \%$ and $10.7 \%$ in dispersed hybrids. The thicker ply blocks (see Table 1) prevented fragmentation, and also caused larger energy release upon carbon fibre fracture while still having the same number of SRPP layers.

The blocked hybrid with $\mathrm{V}_{\mathrm{f}}$ of $8.6 \%$ has an undesirable load drop following the failure of the carbon layer but retains $75 \%$ of its UTS and exhibits a pseudo-plateau. This load retention is related to the gradual delamination between the SRPP and the carbon layer. The final load drop occurs at strains beyond 3\% and is accompanied by gradual debonding, breakage and splitting of the SRPP tapes.

The dispersed hybrid with $\mathrm{V}_{\mathrm{f}}$ of $10.7 \%$ fails more abruptly than the blocked hybrid. The extent of delamination and debonding of the SRPP tapes in this particular dispersed hybrid is limited, because spreading out the carbon plies essentially reduces the carbon ply thickness. This makes the development of delaminations less energetically favourable $[17,18]$, and hence prevents damage diffusion. When examining the peaks in the stress-strain diagram, it can be noticed that the material does not immediately fail after the initial load drop, but still has a slight recovery where the SRPP holds on shortly before it goes to complete failure (see the zoomed-in section in Figure 8). 


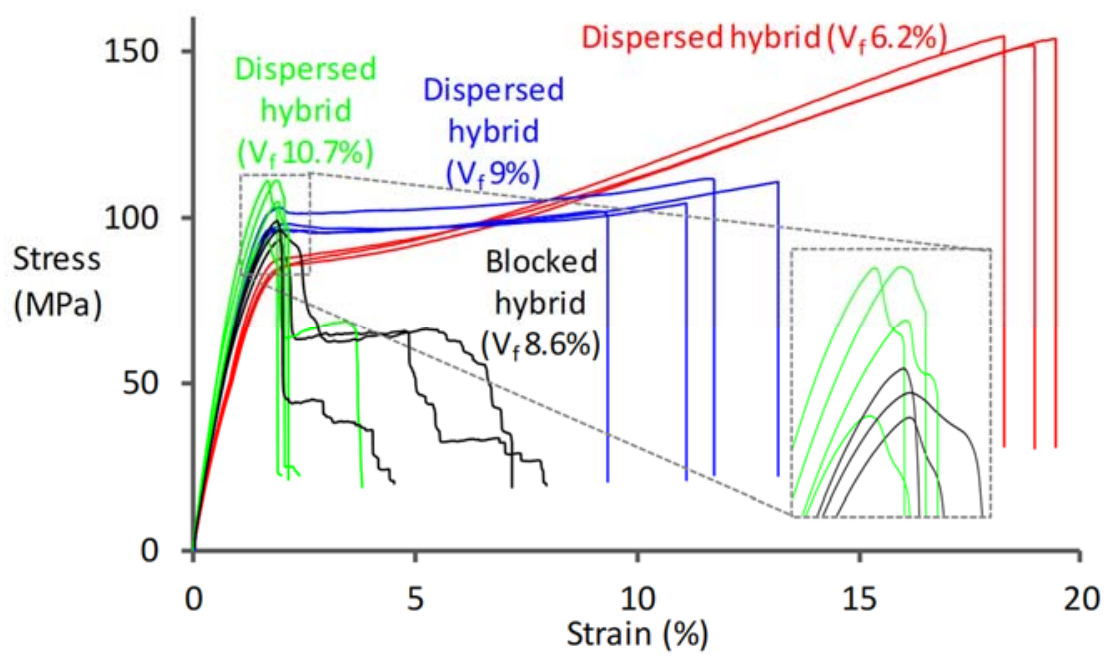

Figure 8: Stress-strain diagrams of all unnotched hybrids, with a closer look at the peaks of the two more brittle hybrids.

\subsubsection{Notched}

Figure 9 summarises the gross stress-strain diagrams of the notched hybrids. The dispersed hybrid with $\mathrm{V}_{\mathrm{f}}=6.2 \%$ is the only one that retained its pseudo-ductility.

Nonetheless, the other hybrids achieved nearly $100 \%$ net strength retention (see Table 3), and will be discussed individually.

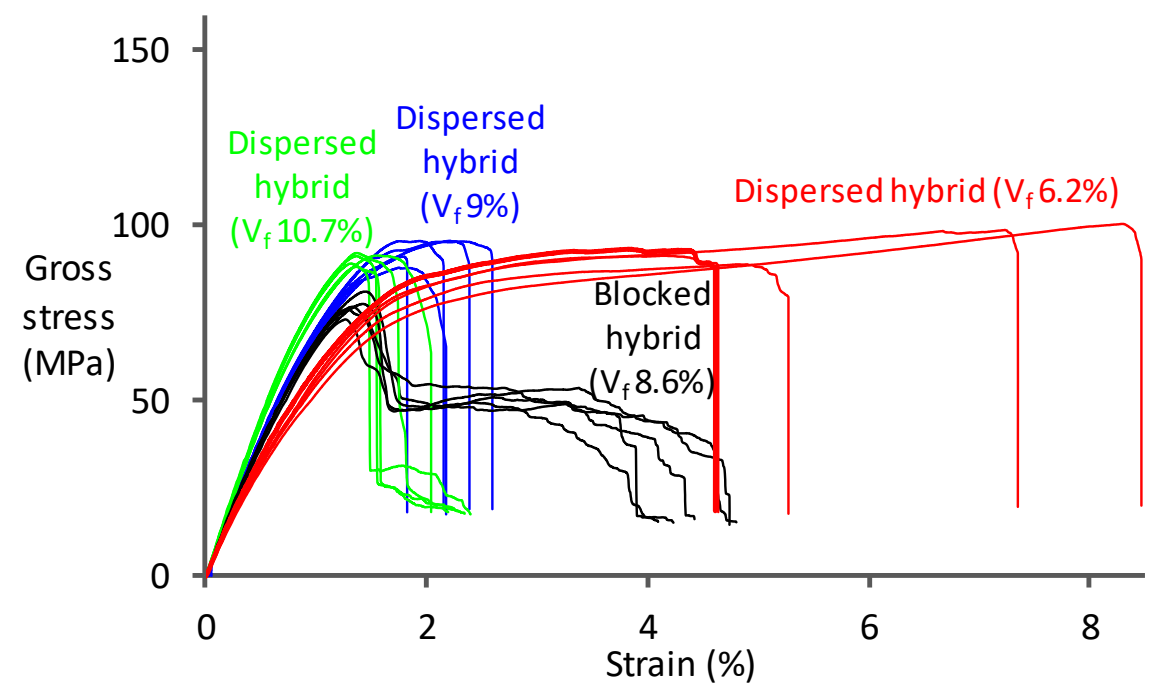

Figure 9: Gross stress-strain diagrams of all the notched hybrids with a $6 \mathbf{m m}$ hole.

Table 3: Results of the OHT tests on the four different hybrids with $6 \mathbf{~ m m}$ diameter holes.

\begin{tabular}{ccccc}
\hline Hybrid & $\begin{array}{c}\text { Gross UTS } \\
(\mathrm{MPa})\end{array}$ & $\begin{array}{c}\text { Strain at UTS } \\
(\%)\end{array}$ & $\begin{array}{c}\text { Gross strength } \\
\text { retention }(\%)\end{array}$ & $\begin{array}{c}\text { Net strength } \\
\text { retention }(\%)\end{array}$ \\
\hline Dispersed $\mathrm{V}_{\mathrm{f}}=6.2 \%$ & $95 \pm 5$ & $5.5 \pm 2.4$ & 62 & 74 \\
Dispersed $\mathrm{V}_{\mathrm{f}}=9.0 \%$ & $93 \pm 4$ & $2.0 \pm 0.3$ & 87 & 105 \\
Dispersed $\mathrm{V}_{\mathrm{f}}=10.7 \%$ & $90 \pm 2$ & $1.4 \pm 0.1$ & 83 & 99 \\
Blocked $\mathrm{V}_{\mathrm{f}}=8.6 \%$ & $77 \pm 3$ & $1.4 \pm 0.1$ & 81 & 98 \\
\hline
\end{tabular}


Figure 10 illustrates the failure process of a representative notched specimen with $\mathrm{V}_{\mathrm{f}}$ $=6.2 \%$ and compares the notched net stress curve with the unnotched curve. After the first crack grows from the hole edge, formation of the damage zone around the hole can be recognised by the whitening of the SRPP (see Figure 10c and d), and it stays visible until the final failure. This SRPP whitening is attributed to a combination of tape debonding, transverse tape cracking and craze/void formation [31], which in turn is triggered by the larger local strain around the hole caused by carbon layer fracture. As stress increases, the carbon layers also fracture at other locations, which causes more white regions to appear (see Figure 10d). This fragmentation of the carbon layers continues until the local stresses reach the maximum strength of SRPP and the specimen fails. Overall, both notched and unnotched pseudo-ductile specimens developed the same failure mechanism and displayed pseudo-ductile behaviour. The unnotched and notched stress-strain behaviour of the $6.2 \%$ hybrid is somewhat similar to the behaviour of the SRPP specimens with films: the failure strains of both composites are similar in the unnotched state, and reduced significantly in the notched state. That reduction is, however, larger for the hybrid than for the SRPP with films.

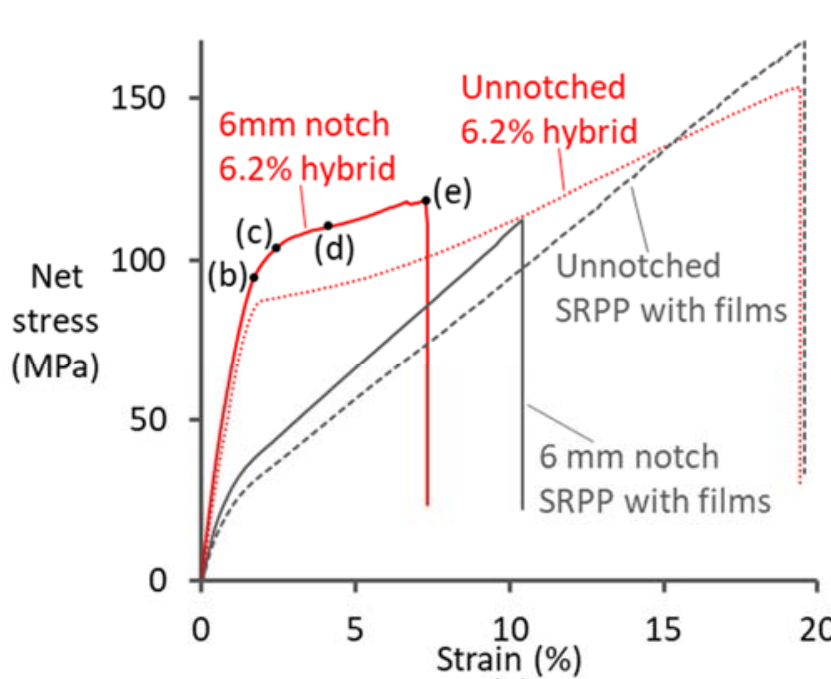

(a)

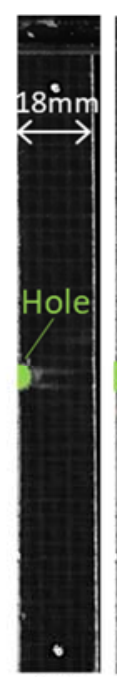

(b)

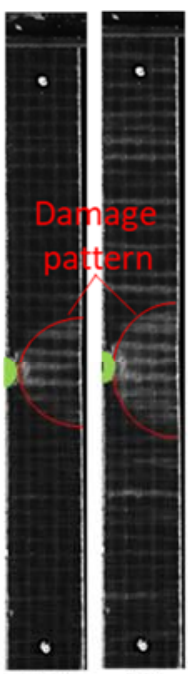

(c)

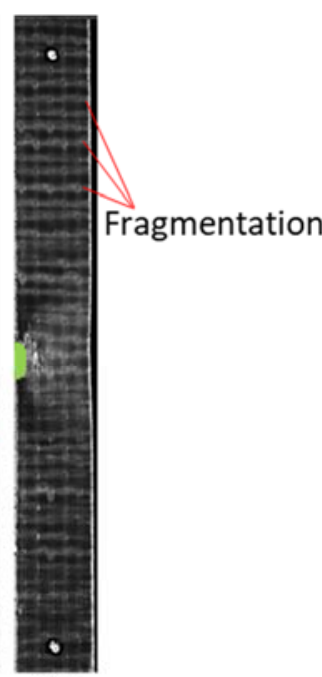

(e)

Figure 10: a) Representative net stress-strain diagrams of the notched and unnotched dispersed hybrid with $V_{f}=6.2 \%$ with images corresponding to: b) first crack initiation from the hole edge, c)

damage zone around the hole, $d$ ) fragmentation of the carbon plies and e) the last image taken before the failure of SRPP layers. The corresponding results for SRPP with films were included for comparison purposes. 
The notched dispersed hybrid with $\mathrm{V}_{\mathrm{f}}=9 \%$ reached only $20 \%$ of its original unnotched strain, but has the highest strength retention of all tested hybrids (see Figure 11a). In the unnotched state, its behaviour was pseudo-ductile, but there was only a small margin between the stresses at which carbon broke (about $100 \mathrm{MPa}$ ) and when SRPP failed (about $110 \mathrm{MPa}$ ). A similar stress margin of $10 \mathrm{MPa}$ between the two failure events is observed with the notched hybrids (see Figure 11). The crack in the carbon layer initiates from the hole edge at $1.2 \%$ strain (see Figure $11 \mathrm{~b}$ ) and grows towards the specimen edge. The maximum stress coincides with the moment the crack reaches the specimen edge (see Figure 11c). The increased local deformations near the hole soon after also cause the SRPP tapes to break (see Figure 11d and e). The strain fields acquired from digital image correlation also confirmed that local strains reached values up to $20 \%$. Delamination and debonding of the SRPP tapes was limited to the notch region.

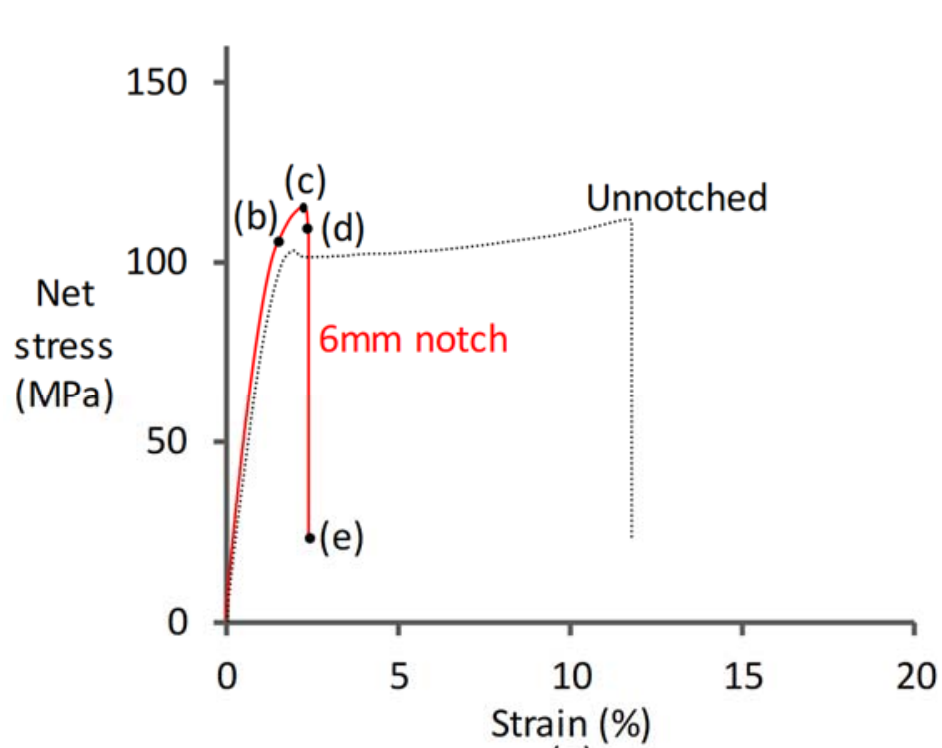

(a)

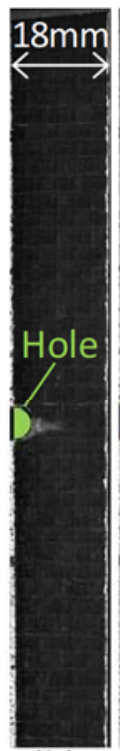

(b)

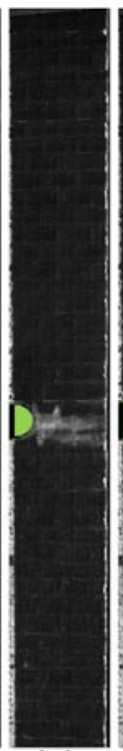

(c)

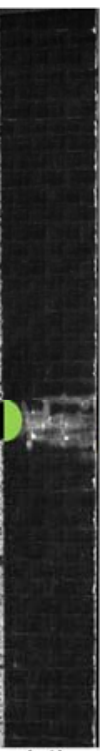

(d)

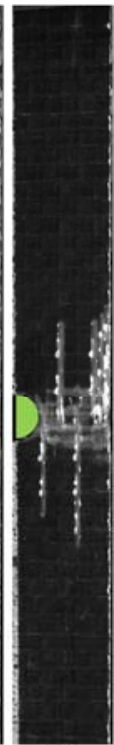

(e)

Figure 11: a) Representative net stress-strain diagrams of the notched and unnotched dispersed hybrid with $V_{f}=9 \%$ with images corresponding to: b) first crack initiation from the hole edge, c) crack reaches sample edge and peak of the tensile curve, d) growth of SRPP damage after the load drop, and e) final failure.

The results of the dispersed hybrid with $\mathrm{V}_{\mathrm{f}}=10.7 \%$ are illustrated in Figure 12 . The notched sample has a $25 \%$ lower failure strain compared to the unnotched reference, but its net strength retention is almost $100 \%$. Both notched and unnotched hybrids fail in a similar manner. There is no fragmentation or delamination, and debonding of SRPP 
tapes develops over a short distance (see Figure 12e). The debonding pattern that is observed in Figure 12d and e is similar to that observed in the unnotched specimens.

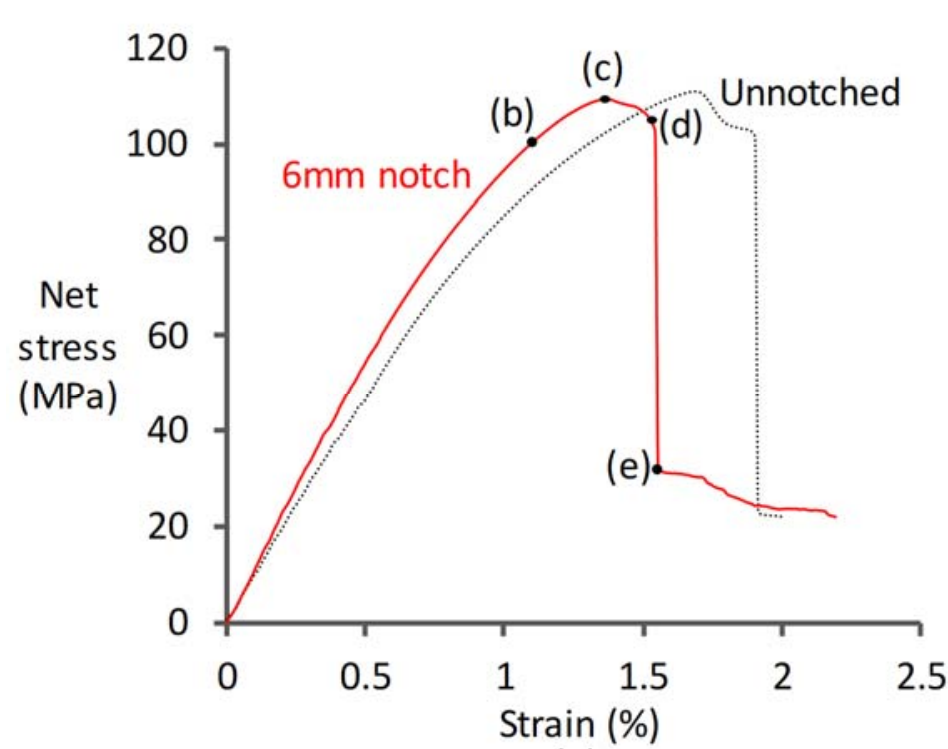

(a)

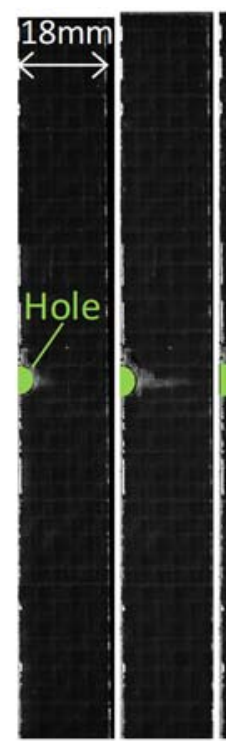

(b)

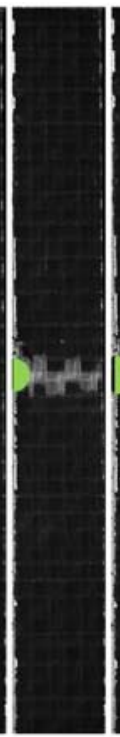

(d) (e)

Figure 12: a) Representative net stress-strain diagrams of the notched and unnotched dispersed hybrid with $V_{f}=10.7 \%$ with images corresponding to: b) first crack initiation from the hole edge, c) the peak of the tensile curve, d) growth of SRPP damage before e) final failure.

The blocked hybrids reveal the same tensile behaviour in its notched state as in the unnotched reference. When using the net available area to calculate stress, the notched sample has its load drop, pseudo-plateau and failure at the same net stress as the unnotched sample (see Figure 13a). The failure process is illustrated in Figure 13 for a representative notched specimen. When the crack has grown until the specimen edge (see Figure 13c), a load drop occurs due to the unstable growth of delamination between the SRPP and the carbon layers (see Figure 13d). The stable growth of this delamination corresponds to the plateau in the tensile curve and continues until the SRPP reaches the limit of its local plastic deformation and starts breaking (see Figure 13e). Stable delamination growth, which corresponded to the plateau in the stress-strain curve, was also observed in the unnotched specimens. The main difference is that in the case of the notched samples, delamination grows in a butterfly pattern. Other damage mechanisms also occur in this specimen, but they are minor compared to the delamination. The three vertical white lines in Figure 13f for example indicate tape/matrix debonding. 


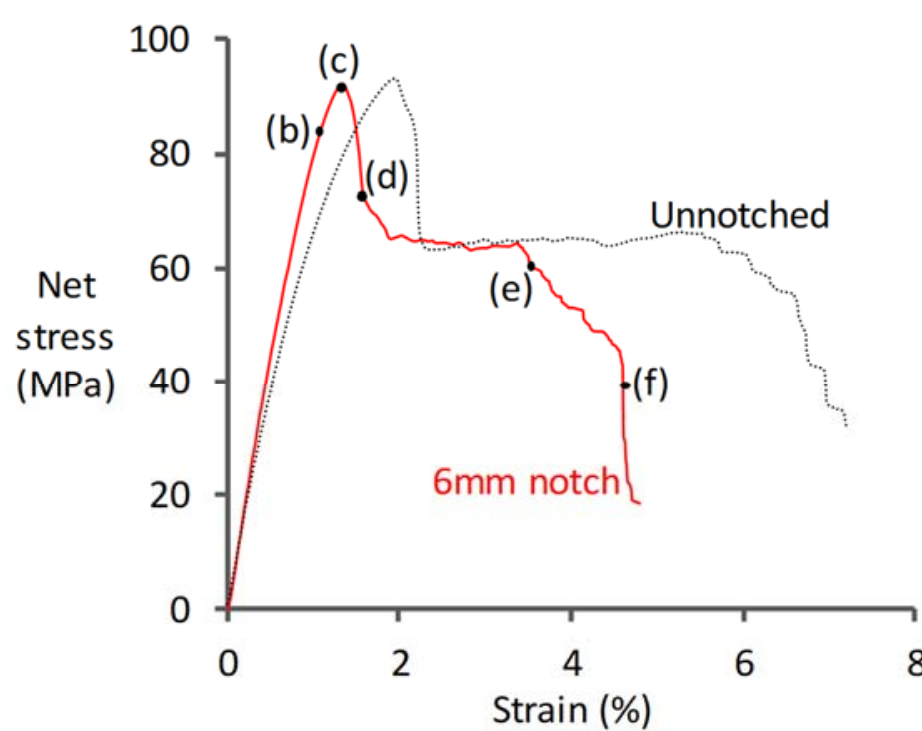

(a)

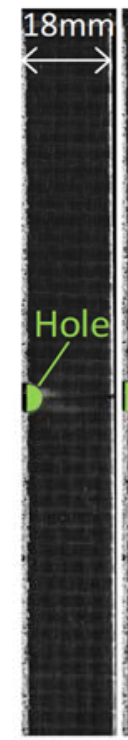

(b)

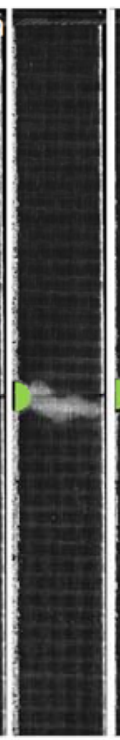

(c)

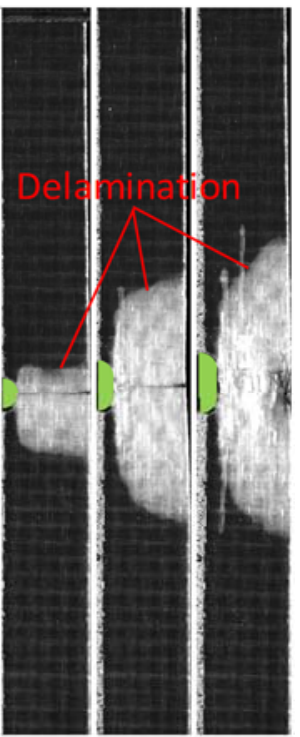

(d) (e)

Figure 13: a) Representative net stress-strain diagrams of the notched and unnotched blocked hybrid with $V_{f}=8.6 \%$ with images corresponding to: b) first crack initiation from the hole edge, c) crack reaches sample edge and peak of the tensile curve, d) growth of SRPP damage after the load drop, and e) growth of delamination after the pseudo-ductile plateau and $f$ ) the onset of final failure when SRPP starts breaking.

\subsection{Discussion}

Dispersed hybrids with $\mathrm{V}_{\mathrm{f}} \leq 9 \%$ demonstrated pseudo-ductile behaviour with

fragmentation of the carbon fibre plies in their unnotched state. The dispersed hybrid with a $\mathrm{V}_{\mathrm{f}}$ of $6.2 \%$ was able to achieve significant pseudo-ductility in its notched state and had a net strength retention of $74 \%$. This hybrid had the highest pseudo-ductile strain of the four hybrids, but nevertheless showed the largest notch sensitivity (see Table 3). The other three hybrids experienced a load drop following the initial failure of the carbon layer but demonstrated a net strength retention of $100 \%$. This is attributed to the fact that the dispersed hybrid with $\mathrm{V}_{\mathrm{f}}=6.2 \%$ has all of its $\mathrm{CF}$ layers separated by an SRPP layer, which effectively implies that this hybrid has thin CF layers or blocks.

Since thin plies/blocks are less energetically favourable for delamination [18], the $6.2 \%$ dispersed hybrid does not show delamination or significant tape debonding (see Figure 10). In all other hybrids, the CF layers are at least partially blocked together, which facilitates delamination and significant tape debonding. This helps to delocalise the stress concentrations from the notch, and allows them to achieve net strength retentions close to $100 \%$. It is clear from this discussion that the good dispersion is driving the good performance of the unnotched $6.2 \%$ hybrid. This also happens to be the hybrid 
layup with the lowest $\mathrm{CF} \mathrm{V}_{\mathrm{f}}$, which is not entirely coincidental. While this is not always the case for fibre-hybrid composites, a low hybrid volume fraction often leads to a good dispersion.

It is noteworthy that failure strain of notched hybrids can be significantly lower than that of the nominal configuration even if they are classified as notch-insensitive. Hybrids tend to develop the same failure mechanisms in notched and unnotched states. However, different damage mechanisms were observed in the case of the dispersed hybrids with $\mathrm{V}_{\mathrm{f}}=9 \%$, because the presence of the hole caused the behaviour to change from pseudo-ductile to brittle. This transition is related to the fact that the net stress was high enough for SRPP to fracture, while the gross stress was too low to trigger fragmentation of the carbon layer away from the hole.

Figure 14 shows the variation of the gross strength retention as a function of the diameter-over-width ratio $\mathrm{D} / \mathrm{W}$ for a theoretically ideal notch insensitive and notch sensitive material. For $\mathrm{D} / \mathrm{W}$ equal to zero, the diagram represents the case of a hole in a plate with infinite width. Additionally, the results of all tested materials are plotted, giving a visual representation of the notch insensitive or sensitive behaviour of the materials. All samples that had a 100\% net strength retention fall on the line of notch insensitivity as could be anticipated. The results of the SRPP laminate without films nicely follow the line for its three different tested hole diameters. Overall, this laminate had the best performance in open-hole tension. It should however be noted that the low interlaminar bonding of such a composite makes it highly prone to delaminations and leads to low flexural and compressive properties. The SRPP composite with interleaved films had the lowest strength retention of the tested composites, and it decreased with growing D/W ratio. Overall, the strength retention obtained with this SRPP composite is comparable to that of other conventional composites like carbon/epoxy laminates. 


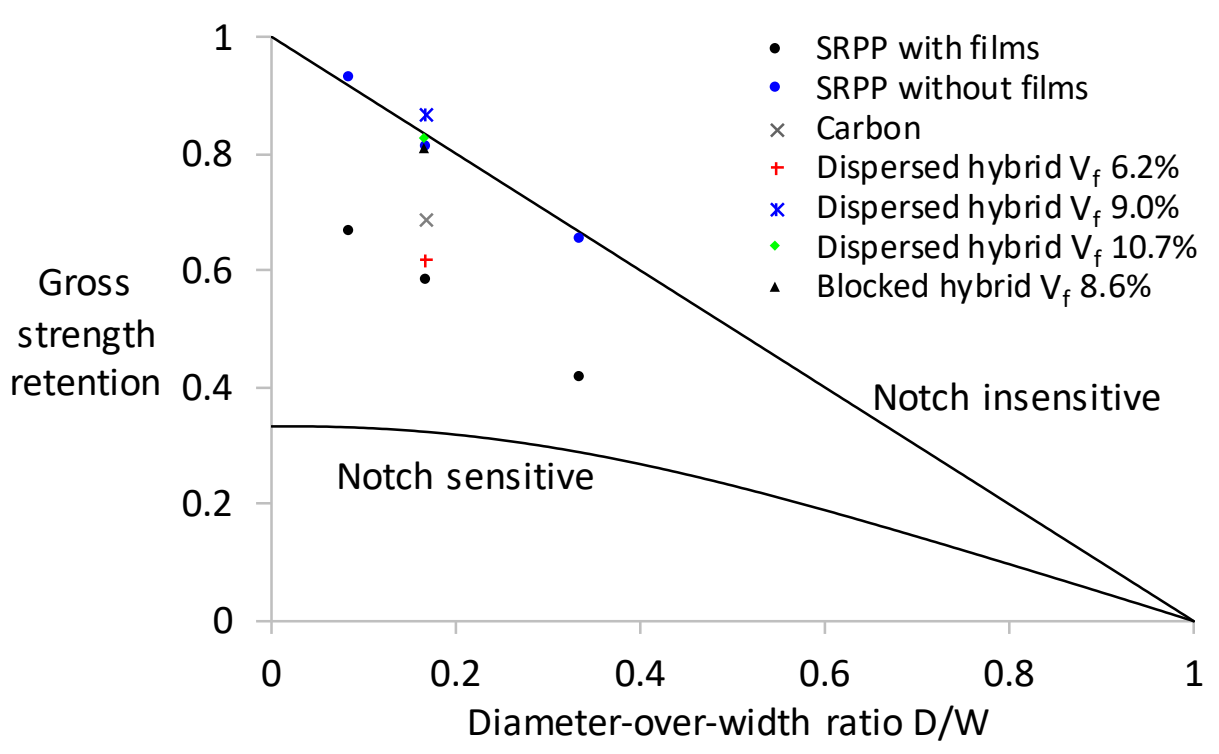

Figure 14: Gross strength retention of all tested composites for different diameter-over-width ratios $\mathrm{D} / \mathrm{W}$, as well as the behaviour of an ideally notch-insensitive and notch-sensitive material. Equations for the lines were taken from [9].

It is also noteworthy to highlight the limitation associated with the use of strength retention to describe the notch sensitivity of a material. For instance, SRPP without films and the hybrids with $\mathrm{V}_{\mathrm{f}}$ of $8.6 \%, 9 \%$ and $10.7 \%$ can all be classified as being notch-insensitive. However, the failure strain retention is different in each case. In fact, the dispersed hybrid with $V_{f}$ of $9 \%$ retains only $17.8 \%$ of its original strain at UTS.

Strain at UTS values and strain retentions are given in Table 4 and Figure 15 to illustrate these differences. The lower strain retentions for the more pseudoductile hybrids seems surprising at first. However, their strain at UTS in the unnotched state was significantly higher, so there was more room for the strain at UTS to decrease. The more pseudoductile hybrids do still have the higher strain at UTS in the notched state, which illustrates that strain retention might be a misleading parameter.

A potentially more relevant way to evaluate notch sensitivity in the future would be using the area underneath the tensile curve instead of strength, as it represents the toughness of a material. These toughness retention values are also shown in Table 4. While the strain and toughness retention values differ, they reveal the same overall trends. Which retention value is most relevant, will depend on the application requirements. 


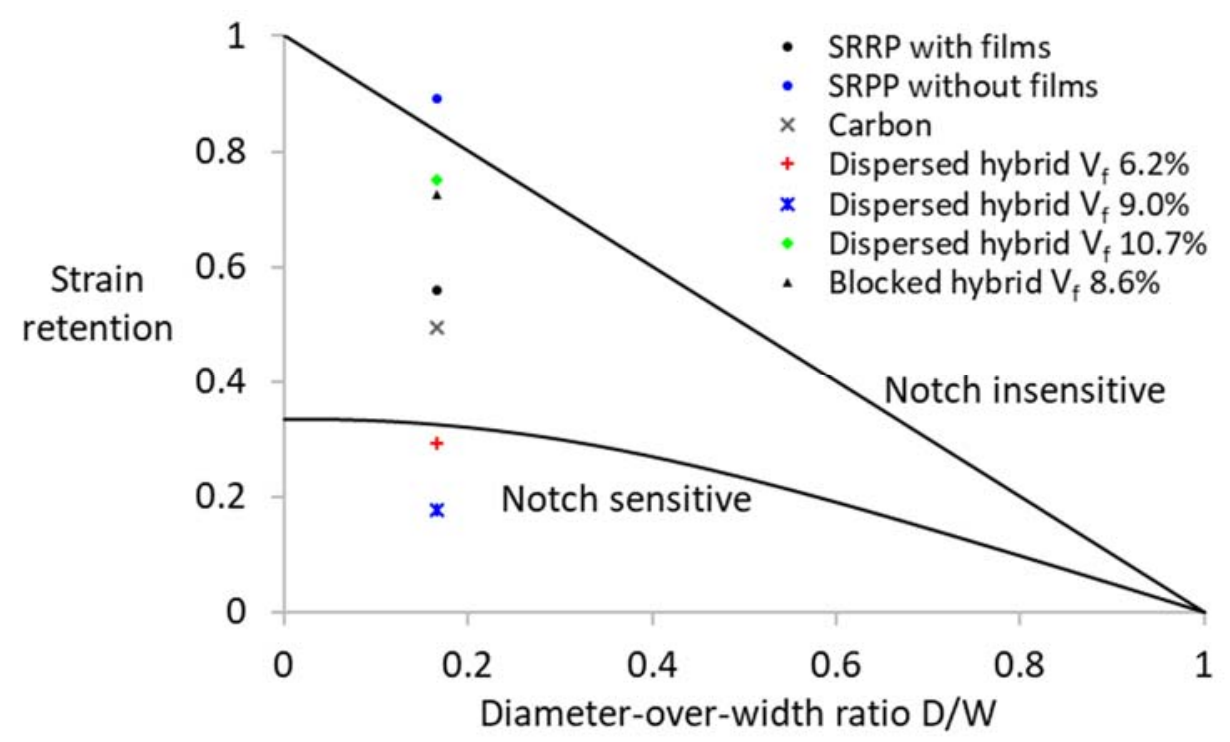

Figure 15: Strain retention for all tested specimens with a $6 \mathrm{~mm}$ hole.

Table 4: Overview of strains at UTS, gross strain retention and gross toughness retention for all tested samples with a $6 \mathrm{~mm}$ hole.

\begin{tabular}{cccccc}
\hline Material & $\begin{array}{c}\mathrm{V}_{\mathrm{f}} \\
(\%)\end{array}$ & $\begin{array}{c}\text { Unnotched strain } \\
\text { at UTS (\%) }\end{array}$ & $\begin{array}{c}\text { Notched (6 mm hole) } \\
\text { strain at UTS (\%) }\end{array}$ & $\begin{array}{c}\text { Strain } \\
\text { retention (\%) }\end{array}$ & $\begin{array}{c}\text { Gross toughness } \\
\text { retention (\%) }\end{array}$ \\
\hline Carbon/PP & 17 & $2.4 \pm 0.1$ & $1.2 \pm 0.1$ & 49.5 & 30.4 \\
SRPP with films & 0 & $18.6 \pm 1.7$ & $10.5 \pm 1.0$ & 56.1 & 35.8 \\
SRPP without films & 0 & $19.4 \pm 1.2$ & $17.3 \pm 0.1$ & 89.1 & 70.2 \\
Dispersed hybrid & 6.2 & $18.8 \pm 0.6$ & $5.5 \pm 2.4$ & 29.4 & 22.6 \\
Dispersed hybrid & 9.0 & $11.2 \pm 1.7$ & $2.0 \pm 0.3$ & 17.8 & 13.5 \\
Dispersed hybrid & 10.7 & $1.9 \pm 0.1$ & $1.4 \pm 0.1$ & 75.1 & 75.3 \\
Blocked hybrid & 8.6 & $1.9 \pm 0.1$ & $1.4 \pm 0.1$ & 72.6 & 68.7 \\
\hline
\end{tabular}

The concept of strength-based notch sensitivity or insensitivity is useful at the early stages of design when failure loads must be estimated quickly. However, it should be used with caution since even in notch-insensitive composites, the failure strains are strongly influenced by the presence of a hole. This effect was pronounced in the case of pseudo-ductile hybrids. This implies that the pseudo-ductile hybrids are good for loadcontrolled applications with notches, but they are not so good for displacementcontrolled applications with notches.

\section{Conclusions}

Notched random carbon mat/PP samples demonstrated a net strength retention of $83 \%$, which is on par with previous studies on discontinuous fibre composites [4,5,20,24]. Woven SRPP with interleaved PP films was found to have an intermediate notch sensitivity with a net strength retention of $70 \%$. The SRPP composites without films 
had net strength retentions of $100 \%$, showing complete notch insensitivity. These

samples had weaker interlayer bonding which resulted in extensive tape debonding and delamination. These sub-critical damage mechanisms proved to be crucial in redistributing the high stresses around the notch. Manufacturing conditions can therefore be optimised to obtain a notch-insensitive self-reinforced composite.

Hybridisation of SRPP with discontinuous carbon fibres shows several interesting possibilities. Three configurations were notch-insensitive, whereas the fourth showed significant progressive pseudo-ductile damage. However, the most pseudo-ductile hybrid was actually the most notch sensitive, as the absence of blocked CF plies prevented delamination and significant tape debonding. Depending on the desired properties, a material can thus be made that has no net strength loss in a notched state or one that does have reduced notched failure strength and strain but can give a premature warning before failure via its pseudo-ductile deformation. The presented results provide insight in how this delicate balance can be achieved.

\section{Acknowledgments}

The authors would also like to acknowledge the funding and the materials provided by Toray Industries, Inc. as well as all the fruitful discussions that have led to the initiation of this project and its swift progress. YS extends his gratitude to FWO Flanders for his postdoctoral fellowship.

\section{References}

[1] Takano M, Nielsen LE. The notch sensitivity of polymeric materials. Journal of Applied Polymer Science. 1976;20(8):2193-2207.

[2] Awerbuch J, Madhukar MS. Notched Strength of Composite Laminates: Predictions and Experiments-A Review. J Reinf Plast Compos. 1985;4(1):3-159.

[3] Wisnom MR, Hallett SR, Soutis C. Scaling Effects in Notched Composites. J Compos Mater. 2010;44(2):195-210.

[4] Lindhagen J, Berglund L. Notch sensitivity and damage mechanisms of glass mat reinforced polypropylene. Polymer Composites. 1997;18(1):40-47.

[5] Qian C, Harper LT, Turner TA, Warrior NA. Notched behaviour of discontinuous carbon fibre composites: Comparison with quasi-isotropic non-crimp fabric.

Composites Part A. 2011;42(3):293-302.

[6] Elbadry EA, Abdalla GA, Aboraia M, Oraby EA. Notch sensitivity of short and 2D plain woven glass fibres reinforced with different polymer matrix composites. J Reinf Plast Compos. 2017;36(15):1092-1098. 
[7] Green BG, Wisnom MR, Hallett SR. An experimental investigation into the tensile strength scaling of notched composites. Composites Part A. 2007;38(3):867-878.

[8] Vaidya RS, Klug JC, Sun CT. Effect of Ply Thickness on Fracture of Notched Composite Laminates. AIAA Journal. 1998;36(1):81-88.

[9] Pilkey WD. Formulas for stress, strain, and structural matrices. Hoboken, USA: John Wiley \& Sons; 2005.

[10] Swolfs Y, Van den fonteyne W, Baets J, Verpoest I. Failure behaviour of selfreinforced polypropylene at and below room temperature. Composites Part A.

2014;65:100-107.

[11] Swolfs Y, Crauwels L, Gorbatikh L, Verpoest I. The influence of weave architecture on the mechanical properties of self-reinforced polypropylene. Composites Part A. 2013;53:129-136.

[12] Schneider C, Kazemahvazi S, Åkermo M, Zenkert D. Compression and tensile properties of self-reinforced poly(ethylene terephthalate)-Composites. Polymer Testing. 2012;32:221-230.

[13] Hine PJ, Ward IM. Hot compaction of woven nylon 6,6 multifilaments. Journal of Applied Polymer Science. 2006;101(2):991-997.

[14] Selezneva M, Swolfs Y, Katalagarianakis A, Ichikawa T, Hirano N, Taketa I, et al. The brittle-to-ductile transition in tensile and impact behavior of hybrid carbon fibre/self-reinforced polypropylene composites. Composites Part A. 2018;109:20-30. [15] Swolfs Y, Meerten Y, Hine PJ, Ward IM, Verpoest I, Gorbatikh L. Introducing ductility in hybrid carbon fibre/self-reinforced composites through control of the damage mechanisms. Compos Struct. 2015;131:259-265.

[16] Tang J, Swolfs Y, Yang M, Michielsen K, Ivens J, Lomov SV, et al.

Discontinuities as a way to influence the failure mechanisms and tensile performance of hybrid carbon fiber/self-reinforced polypropylene composites. Composites Part A. 2018;107:354-365.

[17] Czél G, Wisnom MR. Demonstration of pseudo-ductility in high performance glass/epoxy composites by hybridisation with thin-ply carbon prepreg. Composites Part A. 2013;52:23-30.

[18] Jalalvand M, Czél G, Wisnom MR. Damage analysis of pseudo-ductile thin-ply UD hybrid composites - a new analytical method. Composites Part A. 2015;69:83-93. [19] Wu C-M, Lai W-Y. Mechanical and open hole tensile properties of self-reinforced PET composites with recycled PET fiber reinforcement. Journal of Applied Polymer Science. 2016;133(29):43682.

[20] Toll S, Aronsson C-G. Notched strength of long- and short-fibre reinforced polyamide. Compos Sci Technol. 1992;45(1):43-54.

[21] Hitchen SA, Ogin SL, Smith PA, Soutis C. The effect of fibre length on fracture toughness and notched strength of short carbon fibre/epoxy composites. Composites. 1994;25(6):407-413.

[22] Mallick PK. Effects of hole stress concentration and its mitigation on the tensile strength of sheet moulding compound (SMC-R50) composites. Composites. 1988;19(4):283-287.

[23] Shirrell CD, Onachuk MG. Influence of mold coverage upon the notch strength of R25 sheet molding compound. Composite Materials: Fatigue and Fracture, ASTM STP 9071986. p.

[24] Feraboli P, Peitso E, Cleveland T, Stickler PB, Halpin JC. Notched behavior of prepreg-based discontinuous carbon fiber/epoxy systems. Composites Part A. 2009;40(3):289-299.

[25] Shaari N, Jumahat A, Abdullah SA, Hadderi AZ. Effect of hybridization on openhole tension properties of woven Kevlar/glass fiber hybrid composite laminates. Jurnal Teknologi. 2015;76(9):91-96. 
[26] Haery HA, Zahari R, Kuntjoro W, Taib YM. Tensile strength of notched woven fabric hybrid glass, carbon/epoxy composite laminates. Journal of Industrial Textiles. 2012;43(3):383-395.

[27] Czél G, Rev T, Jalalvand M, Fotouhi M, Longana ML, Nixon-Pearson OJ, et al. Pseudo-ductility and reduced notch sensitivity in multi-directional all-carbon/epoxy thin-ply hybrid composites. Composites Part A. 2018;104:151-164.

[28] Swolfs Y, Gorbatikh L, Verpoest I. Fibre hybridisation in polymer composites: a review. Composites Part A. 2014;67:181-200.

[29] Swolfs Y, Verpoest I, Gorbatikh L. Recent advances in fibre-hybrid composites: materials selection, opportunities and applications. International Materials Reviews. 2019;64(4):181-215.

[30] Swolfs Y, Zhang Q, Baets J, Verpoest I. The influence of process parameters on the properties of hot compacted self-reinforced polypropylene composites. Composites Part A. 2014;65:38-46.

[31] Pae KD, Chu HC, Lee JK, Kim JH. Healing of stress-whitening in polyethylene and polypropylene at or below room temperature. Polymer Engineering and Science. 2000;40(8):1783-1795. 